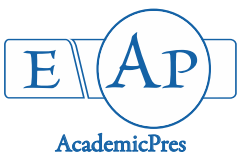

Alia F et al. (2021)

Notulae Scientia Biologicae

Volume 13, Issue 4, Article number 11054

DOI: $10.15835 / \mathrm{nsb} 13411054$

Research Article

\title{
Comparative study of some physicochemical and biological properties of effect host species variation on the relationship Saharan parasitic plant Cistanche violacea (Desf.) Beck.
}

\author{
Fatma ALIA ${ }^{1}$, Atef CHOUIKH ${ }^{1 *}$, Ali Boutlelis DJAHRA ${ }^{1}$, \\ Aida BOUSBIA BRAHIM ${ }^{1}$, Sadok NANI², Ali TLIBA ${ }^{2}$
}

\author{
${ }^{1}$ El Oued University, Faculty of Natural Science and Life, Laboratory Biology, Environment and Health, P.O. Box 789, 39000, \\ El-Oued, Algeria; fatemalia1993@gmail.com; chouikhateff@gmail.com (*corresponding author); \\ djahra_ab@yahoo.fr; bousbia.aida@gmail.com \\ ${ }^{2}$ University of El Oued, VTRS Laboratory, P.O.Box 789,39000,El Oued, Algeria; sadokna@gmail.com; tliba39@yahoo.fr
}

\begin{abstract}
This work aims to study the effect of different host species on physicochemical and biological properties of the Saharan parasitic plant Cistanche violacea that grows parasitized on two hosts Haloxylon articulatum and a Limonistrum guyonianum in the eastern desert of Algeria. The physicochemical characteristics of $C$. violcea showed an affinity for the results of both ash and $\mathrm{pH}$ and it showed a difference in the amount content of carbohydrates and the value of electrical conductivity. For the content of polyphenols, flavonoids, anthocyanins and tannins the highest values were recorded in $C$. violcea, which was parasitized on $H$. articulatum. While, the results of HPLC have identified nine compounds in the crude extracts of the parasitic plants and their hosts in different concentrations. In antioxidant activity, the tannin and anthocyanin extracts from $C$. violcea parasitized on $H$. articulatum showed better inhibition of $\mathrm{DPPH}^{\bullet}$ radical and best the total antioxidant capacity respectively, but the tannins extract of $C$. violcea parasitized on $L$. guyonianum given best reducing power capacity. In SPF assay by UV-Vis spectrophotometry method, all extracts of the parasitic plants showed mild to moderate sun protection. Statically the host variation did not show any significant differences in the physicochemical analysis and the quantitative and qualitative total content of polyphenols. While the significant differences appeared through the antioxidant activity tests, especially between $C$. violcea and its host $H$. articulatum, between $C$. violacea and its host $H$. articulatum and between the two samples of parasitic plants.
\end{abstract}

Keywords: antioxidant activity; biological properties; Cistanche violacea (Desf). Beck.; HPLC; physicochemical characteristics

\section{Introduction}

Parasitic plants are common in nature communities, but are largely ignored in plant community theory. These plants live at the expense of other plants on which they depend for growth and development. Where interactions between a parasitic plant and host appear: display host preferences, reduce host biomass and alter

Received: 18 Aug 2021. Received in revised form: 18 Oct 2021. Accepted: 20 Oct 2021. Published online: 02 Nov 2021.

From Volume 13, Issue 1, 2021, Notulae Scientia Biologicae journal uses article numbers in place of the traditional method of continuous pagination through the volume. The journal will continue to appear quarterly, as before, with four annual numbers. 
host allocation pattern, modify plant community structure and dynamics, and mediate interactions between host plants and other organisms (Penning et al., 2002). On the other, in the parasitic angiosperms, a distinction must be made between root parasites that infect the root system of their hosts and stem parasites that attack the above-ground shoots. This contact occurs, in both, via haustoria which are unique multicellular structures specialized for attachment to and penetration of host tissue (Fahmy et al., 1996).

The parasitism in plants can be defined as a highly successful life strategy and biological mechanism linking different plant species. The parasitic plant grows selectively toward the hosts, by selectively penetrating the host's tissues after contact (Penning et al., 2002).

Cistanche is a genus of the Orobanchaceae family. It is the angiosperm dicotyledonous holoparasitic plants that lack chlorophyll and therefore cannot performs photosynthesis, so it forms an attractive group of phanerogamic root parasites (Ningqun et al., 2017). The occurrence of the genus is restricted to certain arid and semi-arid regions of Africa, Asia and the Mediterranean area including parts of Southern Europe (Penning et al., 2002). In Algerian Sahara is represented by three species (Bougandoura et al., 2016), C. tubulosa which is common to the central Sahara; $C$. tinctorial which is a Sahara Mediterranean, and C. violacea (Desf.) Beck. or Phelipaea violacea Desf. (Le Floch et al., 2010; Zengin et al., 2011) which is an endemic of Northern Africa and locally known Danoun (Zhang et al., 2008; Dhanani et al., 2013).

In the observed and collected areas, $C$. violacea restricted its range in two hosts only, Haloxylon articulatum (Chenopodiaceae) (Bougandoura et al., 2016; Zengin et al., 2011), and on Limonistrum guyonianum (Plumbaginaceae) (Fahmy et al., 1996). The mature body of this holoparasite consists of an underground perennial fleshy tuberous rhizome, flowering stalks that emerge above the ground surface during the springtime (Fahmy et al., 1996). In Algeria, it is scattered on a large area in the Southeast of Algeria (Dhanani et al., 2013), it grows in sandy and salty soil (Fahmy et al., 1996).

The information about $C$. violacea is very scant. Therefore, we identified the main purpose of this work as to study the extent to which host plant variation affected the extracts of the natural products of $C$. violacea (Desf.) Beck. Which grows in the Oued Souf region (Southeast Algeria).

\section{Materials and Methods}

\section{Plant material}

The Danon plant (C. violacea) and its hosts $(H$. articulatum and $L$. guyonianum) were collected in spring 2020 from two areas (Table 1) of the Oued Souf region (Southeast of the Algerian Sahara). The plant is dried, crushed and kept away from moisture and light.

Table 1. Abbreviation and collection area of the studied plants

\begin{tabular}{|c|c|c|}
\hline The studied plants & Abbreviation & Collection area \\
\hline Haloxylon articulatum & $\mathrm{HA}$ & \multirow{2}{*}{$\begin{array}{c}\text { Reguiba } \\
\left(33^{\circ} 42^{\prime} 55^{\prime \prime N} ; 6^{\circ} 40^{\prime} 16^{\prime \prime} \mathrm{E}\right)\end{array}$} \\
\hline Cistanche violcea, which was parasitized to HA & $\mathrm{CH}$ & \\
\hline Limonistrum guyonianum & LG & \multirow{2}{*}{$\begin{array}{c}\text { El-Megran } \\
\left(33^{\circ} 45^{\prime} 08^{\prime \prime N} ; 6^{\circ} 54^{\prime} 39^{\prime \prime} \mathrm{E}\right)\end{array}$} \\
\hline Cistanche violcea, which was parasitized to LG & $\mathrm{CL}$ & \\
\hline
\end{tabular}

\section{Physicochemical characteristics}

Physicochemical parameters such as the percentage of ash values, $\mathrm{pH}$, electrical conductivity and carbohydrates were performed as per references (Dubois et al., 1956; Benesi et al., 2004; Silva et al., 2009) respectively. Where: all these analyses were based on the studied plant's powder. 


\section{Chemicals}

Ascorbic acid (99\%), gallic acid (99\%), acetone (99\%), ethyl acetate (99.8\%), 2, 2-diphenyl-1picrylhydrazyl (DPPH) (99\%), $\mathrm{K}_{3} \mathrm{Fe}(\mathrm{CN})(99 \%)$, dchloromethane (99.8\%), Folin-Denis's (99\%), KCl (99\%), $\mathrm{C}_{3} \mathrm{H}_{3} \mathrm{NaO}_{2}$ (97\%), phosphate buffer $(0.2 \mathrm{~mol}, \mathrm{pH}$ 6.6), quercetin (95\%), chlorogenic acid, p-coumaric acid, vanillic acid, rutin, vanillin and naringenin were procured from Sigma-Aldrich (USA). Aluminum chloride $\left(\mathrm{AlCl}_{3}\right)(99 \%)$, ferric chloride $\left(\mathrm{FeCl}_{3}\right)(99.99 \%)$, sodium carbonate $\left(\mathrm{Na}_{2} \mathrm{CO}_{3}\right)(99.5 \%)$ and trichloroacetic acid (99\%) were purchased from Prolabo (USA). Folin-Ciocalteu reagent (98\%) and methanol (99\%) were obtained from Biochem Chemopharma Co (France). All other reagents used were of analytical grade, Acetonitrile (99.9\%) and acetic acid (99.8\%) of HPLC gradient grade was purchased from Sigma Aldrich (USA).

\section{Preparation of the extracts}

Preparation of methanolic and flavonoids extract

Ten grams $(10 \mathrm{~g})$ of the dry plant were macerated with $150 \mathrm{ml}$ of methanol at room temperature in dark for 24 hours. After filtration, the solvent was evaporated to dryness under reduced pressure in a rotary evaporator at $50{ }^{\circ} \mathrm{C}$, to get the crude extract, which was stored in a place protected from bright light and humidity (Fahmy et al., 1996).

As for flavonoids, they are obtained by adding to this extract a volume of $150 \mathrm{ml}$ of warm distilled water and $150 \mathrm{ml}$ of ethyl acetate and we put the new mixture in a separator funnel. After the separation of the mixture, we got two phases: Ethyl acetate phase and Aqueous phase, then we take the first one and evaporated it in a rotary evaporator at $50^{\circ} \mathrm{C}$ to get the flavonoids extract (phase ethyl acetate) (Chouikh et al., 2020a).

\section{Extraction of tannins}

Thirty grams ( $30 \mathrm{~g}$ ) of dry matter were macerated with $200 \mathrm{ml}$ mixed distilled water and Acetone (3:7) at room temperature in dark for $72 \mathrm{~h}$. After filtration, the Acetone was evaporated under reduced pressure in a rotary evaporator at $50{ }^{\circ} \mathrm{C}$. Then, we added $150 \mathrm{ml}$ of Dichloromethane and we put the whole mixture in a separatory funnel. After the separation of the organic phase and aqueous phase by a separatory funnel, the first one was further extracted with ethyl acetate $(150 \mathrm{ml})$ and evaporated to dryness at $50^{\circ} \mathrm{C}$ (Chouikh et al., 2021).

\section{Extraction of anthocyanins}

The anthocyanins extract was prepared by macerating $25 \mathrm{~g}$ of the powder of the plant in $125 \mathrm{ml}$ acidified methanol $(0.1 \% \mathrm{HCl})$. The extract was agitated and covered until it reached room temperature in dark for 20 h. The samples were filtered and the solid residues were washed with an additional $75 \mathrm{~mL}$ of acidified methanol $(0.01 \% \mathrm{HCl})$. The extract was then concentrated in a rotary evaporator at $30^{\circ} \mathrm{C}$.

The methanolic extract was dissolved in $100 \mathrm{ml}$ of acidified water $(0.01 \% \mathrm{HCl})$. The mixture was centrifuged at $3000 \mathrm{rpm} 30 \mathrm{~min}$ and the supernatant was taken for drying then use for analysis (Longo et al., 2007; Geetha et al., 2011).

\section{Determination of total phenolic content (TPC)}

The amount of total phenolics content in extract was determined according to Folin-Ciocalteu's method of Singleton-Rossi (Chouikh et al., 2020b) with slight modification; $0.2 \mathrm{ml}$ of sample solution were introduced into a test tube containing $1 \mathrm{ml}$ of Folin-Ciocalteu reagent (10\%), and $0.8 \mathrm{ml}$ of $\mathrm{Na}_{2} \mathrm{CO}_{3}$ (7.5\%). After $30 \mathrm{~min}$ incubation at room temperature, the absorbance was measured at $765 \mathrm{~nm}$ with a spectrophotometer. The total phenolic content was expressed as $\mathrm{mg}$ of gallic acid equivalents per gram of extract. 
Determination of total flavonoid content (TFC)

The total content of flavonoids was measured according to the method by Chouikh et al. (2018). $1 \mathrm{ml}$ of the sample solution was blended with $1 \mathrm{ml}$ of $\mathrm{AlCl}_{3}(2 \%)$. After stirring the solution, it incubated for $15 \mathrm{~min}$ at room temperature. The absorbance was measured at $430 \mathrm{~nm}$ with a spectrophotometer. The content of flavonoids was expressed as mg equivalents Quercetin per gram of extract.

\section{Determination of total tannin content (TTC)}

The content of tannins was measured based on Folin-Denis's assay described by Suresh et al. (2010). About $0.5 \mathrm{ml}$ of Folin and $1 \mathrm{ml}$ of $\mathrm{NaCO}_{3}(35 \%)$ were added to $100 \mu \mathrm{l}$ of the diluted sample, volume was made to $100 \mathrm{ml}$ with distilled water. The mixture was left to read for $30 \mathrm{~min}$ and the absorbance was measured at 700 $\mathrm{nm}$. The amounts of tannins were expressed as $\mathrm{mg}$ of gallic acid equivalents per gram of extract.

\section{Determination of total anthocyanin content (TAC)}

The total anthocyanin content was determined using the method described by Cam et al. (2009) with minor modifications. TAC was evaluated by a $\mathrm{pH}$ differential method using two buffer systems: $\mathrm{KCl}[\mathrm{pH} 1.0$ $(0.025 \mathrm{M})]$ and $\mathrm{C}_{3} \mathrm{H}_{3} \mathrm{NaO}_{2}[\mathrm{pH} 4.5(0.4 \mathrm{M})]$. Briefly, 2 aliquots $(200 \mu \mathrm{l})$ of the extract were mixed with $1.8 \mathrm{ml}$ of corresponding buffers. The absorbance was then measured at $510 \mathrm{~nm}$ and $700 \mathrm{~nm}$.

TAC of samples ( $\mathrm{mg}$ cyanidin-3-glucoside / $100 \mathrm{~g}$ of extract) was calculated by the following equation:

$\mathrm{TAC}=(\mathrm{A} \times \mathrm{MW} \times \mathrm{DF} \times 100) / \mathrm{MA}$

Where; $\mathrm{A}=\left(\mathrm{A}_{510}-\mathrm{A}_{700}\right) \mathrm{pH}_{1.0}-\left(\mathrm{A}_{510}-\mathrm{A}_{700}\right) \mathrm{pH}_{4.5} ; \mathrm{MW}$ : molecular weight $(449.2 \mathrm{~g} / \mathrm{mol})$; DF: dilution factor (10); MA: molar absorptivity of cyanidin-3-glucoside (26.9 1/mol.cm).

\section{Analyze qualitative by HPLC}

In this study, we have used HPLC with UV-Vis type Shimadzu LC 20 AL equipped with the universal injector (Hamilton $25 \mu \mathrm{L}$ ), an analytical column used was a Shim-pack VP-ODS C18 $(4.6 \mathrm{~mm} \times 250 \mathrm{~mm}, 5$ $\mu \mathrm{m}$ ), UV-VIS detector SPD 20A type (Shimadzu) was used detection for the analysis of phenolic compounds of crude extract. The mobile phase consisted of gradient elution of a mixture of acetonitrile and acetic acid $0.1 \%$, and the reverse phase chromatography analyses were carried out with non-polar aliphatic residues. The flow rate was $1 \mathrm{~mL} / \mathrm{min}$, and the injection volume was $0.45 \mu \mathrm{l}$. The monitoring wavelength was $268 \mathrm{~nm}$, and the injected volume of samples and standards phase was $20 \mu$.

Identification of some compounds was done by comparison of their retention time and UV absorption spectrum with those of the standards.

\section{Evaluation of antioxidant activity}

$\underline{\mathrm{DPPH}} \cdot$ free radical scavenging

The DPPH ${ }^{\bullet}$ scavenging activity of the extracts was measured by using the modified method of Rebiai $e t$ al. (2015). Briefly, $1 \mathrm{ml}$ of each extract at different concentrations was added to $1 \mathrm{ml}$ of DPPH solution $(0.1 \times$ $10^{-3} \mathrm{~mol}$ ) in methanol. After incubation for $15 \mathrm{~min}$ at room temperature, the absorbance was measured at 517 $\mathrm{nm}$. The inhibition activity was calculated in the following way (Chaouche et al., 2013):

$\mathrm{I}(\%)=\left[\left(\mathrm{A}_{\mathrm{c}}-\mathrm{A}_{\mathrm{s}}\right) / \mathrm{A}_{\mathrm{c}}\right] \times 100$

Where: $A_{c}$ : Absorbance of the control. $A_{s}$ : Absorbance of the sample. The $\mathrm{IC}_{50}(50 \%$ of free radical inhibition of extract) was calculated from equation linear of concentration by a percentage of inhibition. The lower the $\mathrm{IC}_{50}$ value indicates high antioxidant capacity (Truong et al., 2019).

\section{Reducing power assay}

According to the method of Huda-Faujan et al. (2009). Briefly, $0.5 \mathrm{ml}$ of the extracts at various concentrations was mixed with $1.25 \mathrm{ml}$ of a phosphate buffer $(0.2 \mathrm{~mol}, \mathrm{pH} 6.6)$ and $1.25 \mathrm{ml}$ of potassium ferrocyanide $\left[\mathrm{K}_{3} \mathrm{Fe}(\mathrm{CN})\right](1 \%)$. The mixture was incubated in a hot bath at $50^{\circ} \mathrm{C}$ for $20 \mathrm{~min}$. Then, $1.25 \mathrm{ml}$ 
of trichloroacetic acid (10\%) was added, and centrifuged at $3000 \mathrm{rpm}$ for $10 \mathrm{~min}$. A $1.25 \mathrm{ml}$ aliquot of the supernatant, mixing it with $0.25 \mathrm{ml}$ of $\mathrm{FeCl}_{3}(0.1 \%)$ and diluting it with $1.25 \mathrm{ml}$ of distilled water, the absorbance was measured at $700 \mathrm{~nm}$. Ascorbic acid was used as a positive control.

\section{Determination of total antioxidant capacity (TAC)}

Phosphomolybdate assay system was used to determine the total antioxidant activity of various fractions extract, which that determined by the method described by Zengin et al. (2011). $150 \mu$ l of extract solution was mixed with $1.5 \mathrm{~mL}$ reagent solution [6 M: sulfuric acid, $28 \mathrm{mM}$ : sodium phosphate and $4 \mathrm{mM}$ : ammonium molybdate], and stirred well then left for $1 \mathrm{~h}$ in a water bath at $95^{\circ} \mathrm{C}$. After the mixture had cooled to room temperature, the mean of the absorbance values was measured at $695 \mathrm{~nm}$. The antioxidant capacity of extracts was evaluated as mg equivalents ascorbic acid per gram of extract (mg AA E/g extract).

\section{Determination of sun protection factor (SPF) by UV-Vis spectrophotometry}

The Determination of the effectiveness of protection against $U V$ rays carried out in vitro by determining the SPF value by UV-Vis spectrophotometry. Briefly, according to as reported in Dutra et al. (2004), this factor is determined by calculating the difference in the spectroscopy readings of an alcohol solution $(0.5 \mathrm{mg} / \mathrm{ml})$ in the spectral range from $290 \mathrm{~nm}$ to $320 \mathrm{~nm}$, where; the amount of spectral transition is determined by $5 \mathrm{~nm}$. According to the following law:

$\mathrm{SPF}=\mathrm{CF} \times \sum \mathrm{EE}(\lambda) \times \mathrm{I}(\lambda) \times \operatorname{Abs}(\lambda)$

Where; EE: erythemal effect spectrum; I: solar intensity spectrum; Abs: absorbance of sunscreen product; CF: correction factor $(=10)$.

The values of EE x I (Table 2) constants are predetermined by Mbanga et al. (2015).

Table 2. Normalized product function used in the calculation of SPF

\begin{tabular}{|c|c|}
\hline Wavelength $(\mathrm{nm})$ & EE x I (normalized) \\
\hline 290 & 0.0150 \\
\hline 295 & 0.0817 \\
\hline 300 & 0.2874 \\
\hline 305 & 0.3278 \\
\hline 310 & 0.1864 \\
\hline 315 & 0.0837 \\
\hline 320 & 0.0180 \\
\hline Total & 1 \\
\hline
\end{tabular}

The results were compared to categories of sunscreens in Table 3 according to Schalka and Reis (2011).

Table 3. Categories of sunscreens based on the value of the SPF

\begin{tabular}{|l|c|}
\hline \multicolumn{1}{|c|}{ Protection Level } & SPF Value \\
\hline Maximum & $>50$ \\
\hline High & $30-50$ \\
\hline Medium & $15-30$ \\
\hline Low & $2-15$ \\
\hline
\end{tabular}

\section{Statistical analysis}

All value was the mean \pm SD in triplicates. The data were analyzed by an analysis of variance two-way (ANOVA) $(\mathrm{P}<0.01)$; using Excel software (Version 2016) which we used to carry out the tests as well as the curves. 


\section{Results}

\section{Preliminary physicochemical characteristics}

The results obtained for the quantitative determination of some analysis physicochemical of the studied plants are exhibited in Table 4. The ash content specifically refers to the total value of minerals in plant matter. It is generally agreed that the amount of water in the plant has an important influence on the proportion of the mineral matter, which is a determinant of the ash ratio. The $\mathrm{pH}$ values of parasitic plants were almost similar; it also converges between CH plant and its host; while it differs between CL and its host. The studied plants differed in terms of their carbohydrate content. The maximum of this content was observed in parasitic plants and minimum in host plants.

In general, the analytical results showed that the best ratios and values for these parameters were in the host plants (LG and HA respectively). While; the results of comparing the two parasitic plants for all the studied characteristics showed that, the average values of the CL plant best than one recorded at the CH plant. Statistically, they had no significant differences $(\mathrm{P}>0.01)$ between them and their hosts.

Table 4. Physicochemical analysis of the studied plants

\begin{tabular}{|l|c|c|c|c|}
\hline & Ash $\%$ & $\mathrm{pH}$ & $\mathrm{EC}(\mathrm{mS} / \mathrm{cm})$ & Car $(\mathrm{mg} / \mathrm{g})$ \\
\hline HA & 15.92 & 5.77 & 5.6 & $11.85 \pm 0.036^{* *}$ \\
\hline CH & 9.06 & 5.35 & 5.27 & $31.16 \pm 0.325^{* *}$ \\
\hline LG & 21.04 & 7.52 & 8.88 & $15.02 \pm 0.536^{* *}$ \\
\hline CL & 11.13 & 5.63 & 7.05 & $43.83 \pm 0.352^{* *}$ \\
\hline
\end{tabular}

EC: electrical conductivity; Car: carbohydrates. Results are expressed as mean of 3 values \pm standard deviation, ${ }^{* *}$ : Significantly different at $\mathrm{p}<0.01$.

\section{Evaluation quantitative and qualitative of polyphenol content in methanolic extracts}

Our results in Table 5 are a contribution to studying the effect of parasitism relationship on the phytochemical content of the host plant and the extent to which this content varies among the parasitic plant when its host is different. As shown in Table 5, there is a marked variation in the polyphenol content in the parasites and host plants, with TPC ranging from 36.372 to $16.105 \mathrm{mg} \mathrm{GAE} / \mathrm{g}$ Ex and 27.516 to $5769 \mathrm{mg}$ $\mathrm{QE} / \mathrm{g}$ Ex in the PFC. Whereas, TTC and TAC ranged from 0.222 to $0.077 \mathrm{mg} \mathrm{GAE} / \mathrm{g}$ Ex and 0.423 to 0.176 mg C-3-GE/g Ex; respectively. The crude extracts of studied plants showed a difference to each other considerably concerning for to the total polyphenols compounds. Where the difference appeared between the host and the parasitic plant. the variance was also clear between the parasitic plants themselves.

This content of the polyphenol and its fractions can be arranged between parasitic plants and their hosts; and among the parasitic plants among themselves are as follows: $\mathrm{CH}>\mathrm{HA}$ excluding for TAC; $\mathrm{HA}>\mathrm{CH}, \mathrm{LG}$ $>\mathrm{CL}$ and $\mathrm{CH}>\mathrm{CL}$.

Table 5. The polyphenol content and its fractions of the studied plants

\begin{tabular}{|l|c|c|c|c|}
\hline \multicolumn{1}{|c|}{ Plant } & TPC & TFC & TTC & TAC \\
\hline HA & $16.105 \pm 0.768^{* *}$ & $10.362 \pm 0.036$ & $0.077 \pm 0.003^{* *}$ & $0.417 \pm 0.165$ \\
\hline CH & $24.248 \pm 0.512^{* *}$ & $11.166 \pm 0.325$ & $0.222 \pm 0.001^{* *}$ & $0.200 \pm 0.001$ \\
\hline LG & $36.372 \pm 0.768^{* *}$ & $27.516 \pm 0.536^{* *}$ & $0.203 \pm 0.001^{* *}$ & $0.423 \pm 0.031$ \\
\hline CL & $19.055 \pm 0.197^{* *}$ & $5.769 \pm 0.353^{* *}$ & $0.121 \pm 0.002^{* *}$ & $0.167 \pm 0.047$ \\
\hline
\end{tabular}

Results are expressed as mean of 3 values \pm standard deviation, ${ }^{* *}$ : Significantly different at $\mathrm{p}<0.01$.

Linear correlation coefficients were calculated to determine if there were any relationships between the parasitic plants and their hosts; and among the parasitic plants among themselves (Table 6), each of these plants showed a highly significant correlation among themselves. 
Table 6. Correlation coefficients among the polyphenol content and its fractions in the studied plants

\begin{tabular}{|l|c|c|c|c|}
\hline \multicolumn{1}{|c|}{ Plant } & HA & CH & LG & CL \\
\hline HA & 1 & & & \\
\hline CH & 0.983091 & 1 & & \\
\hline LG & 0.994128 & 0.95797 & 1 & 1 \\
\hline CL & 0.939109 & 0.98605 & 0.89689 & \\
\hline
\end{tabular}

\section{Analyze qualitative by HPLC}

In the analysis of the chromatographic; we were able to know the total number of phenolic compounds for each extract (Figure 1). According to the retention time of the standards, we were able to identify and determine the concentrations of some of them (Table 7).

The results showed that the host plants contained the largest number of peaks, which 71 peaks in an extract of HA and 60 compounds in extract of LG, five of them being known compounds with different structures and concentrations (Table 7). While the convergence of their number in the extracts of parasitic plants $\mathrm{CH}$ and CL. Where; seven phenolic compounds were characterized from the crude extract of $\mathrm{CH}$ (gallic acid, chlorogenic acid, p-coumaric acid, vanillin, rutin, naringin and quercetin). While; four compounds were identified in the crude extract of CL: gallic acid, chlorogenic acid, rutin and naringin.

Table 7. The number of peaks and concentration of some phenolic acids and flavonoids compounds in the extracts of the studied plants

\begin{tabular}{|c|c|c|c|c|c|c|}
\hline \multicolumn{3}{|c|}{ Extracts } & $\mathrm{HA}$ & $\mathrm{CH}$ & LG & $\mathrm{CL}$ \\
\hline \multicolumn{3}{|c|}{ Number of peaks } & 71 & 57 & 60 & 56 \\
\hline Phenolic compounds & Ret. time & Equation & \multicolumn{4}{|c|}{ Quantity ( $\mu \mathrm{g} / \mathrm{g}$ extract) } \\
\hline Gallic Acid & 5.29 & $y=54681 x$ & / & 419.477 & 1835.211 & 215.980 \\
\hline Chlorogenic Acid & 13.392 & $y=21665 x$ & 267.658 & 404.883 & / & 534.937 \\
\hline Vanilic Acid & 15.531 & $y=65077 x$ & 26.476 & 1 & 1 & 1 \\
\hline Caffiec Acid & 16.277 & $y=84066 x$ & / & I & 459.779 & / \\
\hline Vanilin & 21.46 & $y=58930 x$ & 88.193 & 14.251 & 560.550 & 1 \\
\hline p-Coumaric Acid & 23.817 & $y=49495 x$ & / & 48.243 & I & / \\
\hline Rutin & 28.37 & $y=28144 x$ & 1926.499 & 7.369 & / & 94.862 \\
\hline Naringin & 34.788 & $y=19379 x$ & 117.251 & 494.133 & 1977.089 & 1590.196 \\
\hline Quercetin & 45.047 & $y=45378 x$ & 1 & 554.670 & 1561.484 & 1 \\
\hline
\end{tabular}

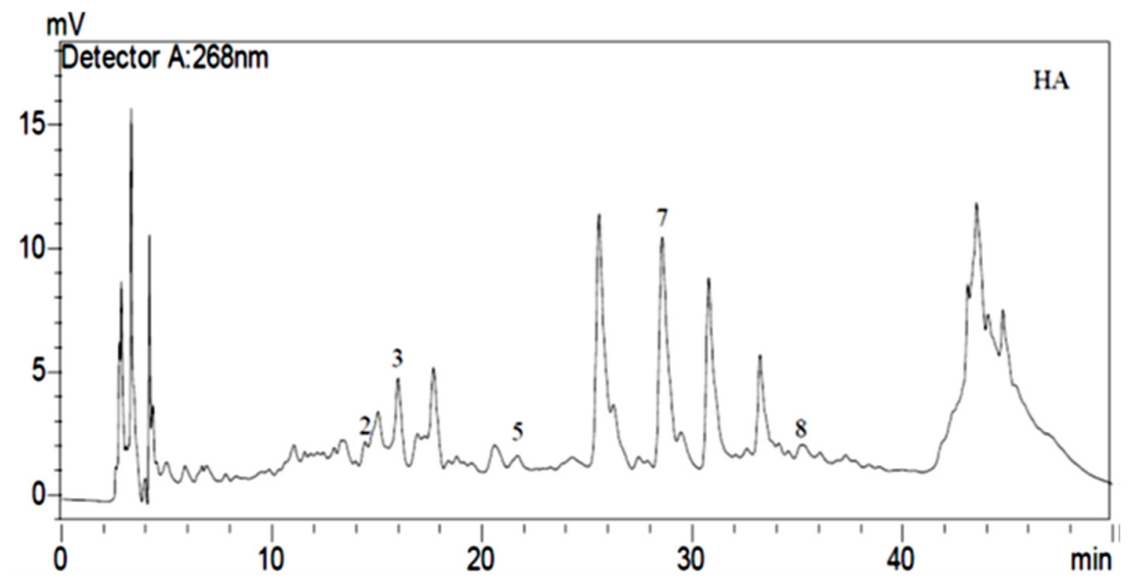




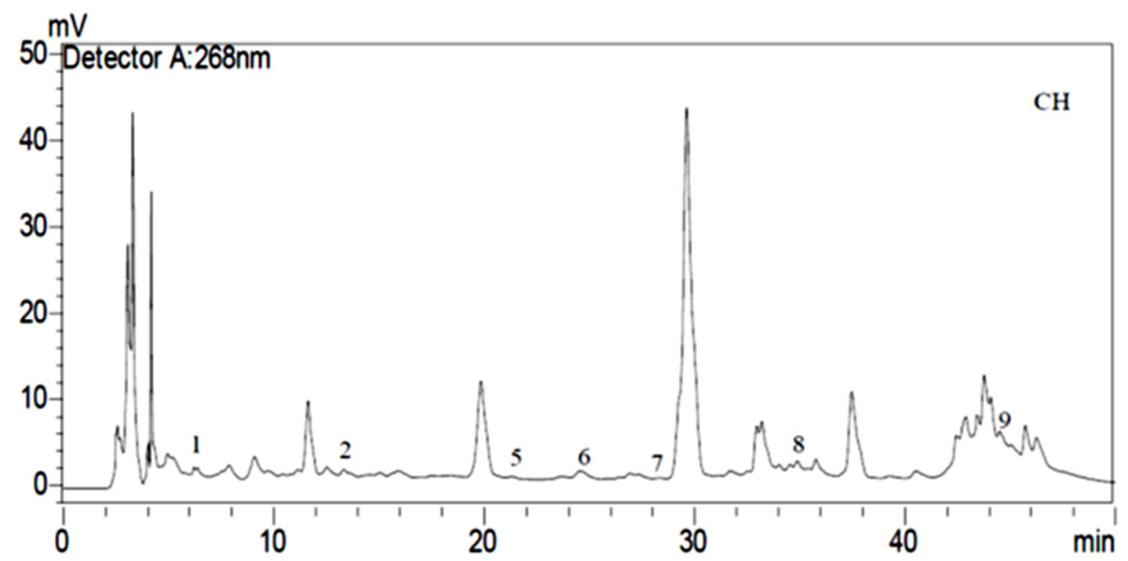

$\mathrm{mV}$

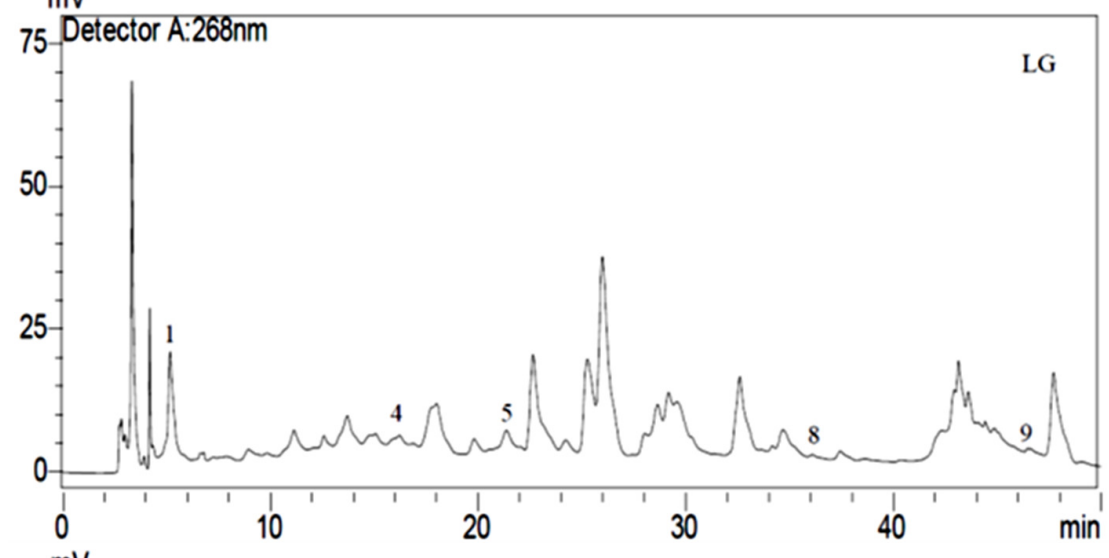

$\mathrm{mV}$

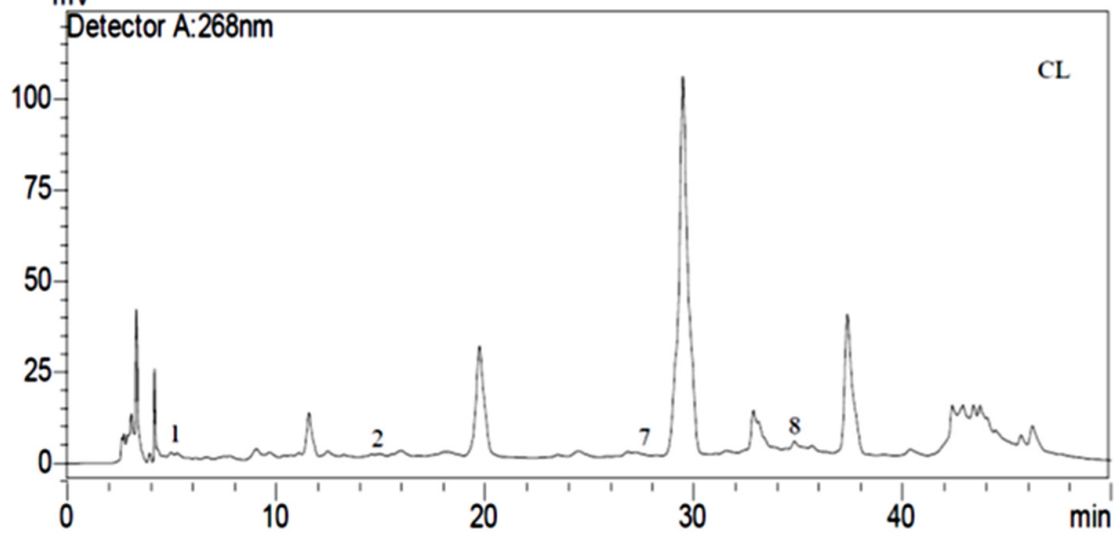

Figure 1. HPLC chromatograms of the studied plants extracts: 1: Gallic acid; 2: Chlorogenic acid; 3: Vanillic acid; 4: Caffiec acid; 5: Vanilin; 6: p-Coumaric acid; 7: Rutin; 8: Naringin; 9: Quercetin.

\section{Evaluation of Antioxidant activity}

\section{$\underline{\mathrm{DPPH}}{ }^{*}$ test scavenging}

The extracts of parasitic plants were compared with those of the ascorbic acid standard (AA), the values for $\mathrm{IC}_{50}$ of the extracts ranged from $0.011 \pm 0.003 \mathrm{mg} / \mathrm{ml}$ to $0.057 \pm 0.001 \mathrm{mg} / \mathrm{ml}$ while $\mathrm{IC}_{50}$ of AA was $0.015 \pm 0.001 \mathrm{mg} / \mathrm{ml}$, extracts of CL $\left(\mathrm{IC}_{50}=0.011 \pm 0.002\right.$ to $\left.0.014 \pm 0.001 \mathrm{mg} / \mathrm{ml}\right)$ showed better DPPH scavenging activities than extracts of $\mathrm{CH}$, with no significant difference between them $(\mathrm{P}<0.01)$. When compared to AA, flavonoids and tannins extracts exhibited top antioxidant abilities to reduce DPPH radicals 
for both parasites' plants. As for the host's plants, HA showed little free radical inhibitory activity in all its extracts, while LG was a high inhibitory of DPPH` free radical (Figure 2).

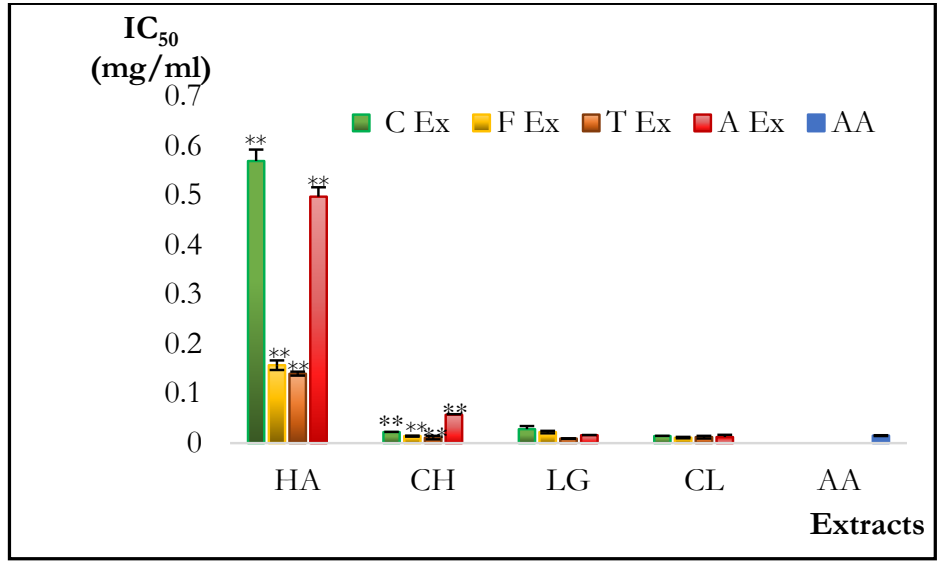

Figure 2. DPPH $\bullet$ Free radical scavenging by the extracts of plants and positive control **: Significantly different at $\mathrm{p}<0.01$.

\section{Reducing power assay}

The reduction capacity of all extracts was tested with increasing concentration; however, its reducing power was inferior to AA.

The extracts of parasitic plants showed medium antioxidant power by reducing power ability. The reduction capacity of extracts of $\mathrm{CL}$ was the highest among the tested extracts with a an $\mathrm{EC}_{50}$ ranged from 0.055 to $0.378 \mathrm{mg} / \mathrm{ml}$, followed by extracts of $\mathrm{CH} 0.140$ at $0.870 \mathrm{mg} / \mathrm{ml}$. While $\mathrm{EC}_{50}$ of the standard $0.015 \pm 0.006 \mathrm{mg} / \mathrm{ml}$. As for comparing the extracts between them, it was shown that the tannin extract had the best reactive ability for the $\mathrm{Fe}^{+3}$ atoms in most of the studied plants. On the other hand, the host plant LG showed better efficiency than the other host plant HA (Figure 3).

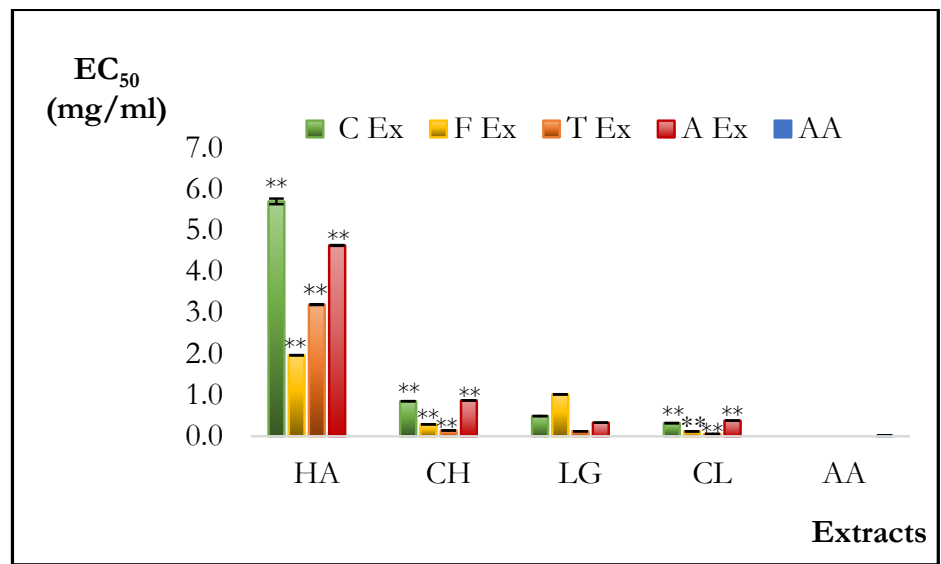

Figure 3. A comparison between different plant extracts and positive controls in reducing power assay ${ }^{* *}$ : Significantly different at $\mathrm{p}<0.01$.

\section{Total antioxidant capacity (TAC)}

The antioxidant capacities of the extracts were measured through the total antioxidant activity estimated by the phosphomolybdenum method. Results showed that the all samples had significant potent antioxidant capacity. 
The comparison of the different extracts of parasitic plants showed that the $\mathrm{CH}$ was more active than the CL. The concentrations of TAC for extracts of $\mathrm{CH}$ and extracts of $\mathrm{CL}$ were ranging between $71.317 \pm 0.006$ to $423.646 \pm 0.051 \mu \mathrm{g} \mathrm{E} \mathrm{AA} / \mathrm{g}$ Ex and $169.102 \pm 0.013$ to $488.493 \pm 0.060 \mu \mathrm{g} \mathrm{E} \mathrm{AA} / \mathrm{g} \mathrm{Ex}$, respectively, as for $\mathrm{BHT}$ the standard reference, it was estimated at $555.002 \pm 0.096 \mu \mathrm{g} \mathrm{E} \mathrm{AA/g} \mathrm{Ex.} \mathrm{The}$ anthocyanin extract showed the best total antioxidant capacity in all studied samples except for the LG sample, the best capacity appeared in the flavonoid extract. In general, the antioxidant capacity of the extracts of studied plants was in the order of $\mathrm{HA}>\mathrm{CH}$, and $\mathrm{CL}>\mathrm{LG}$, and $\mathrm{CL}>\mathrm{CH}$ (Figure 4).

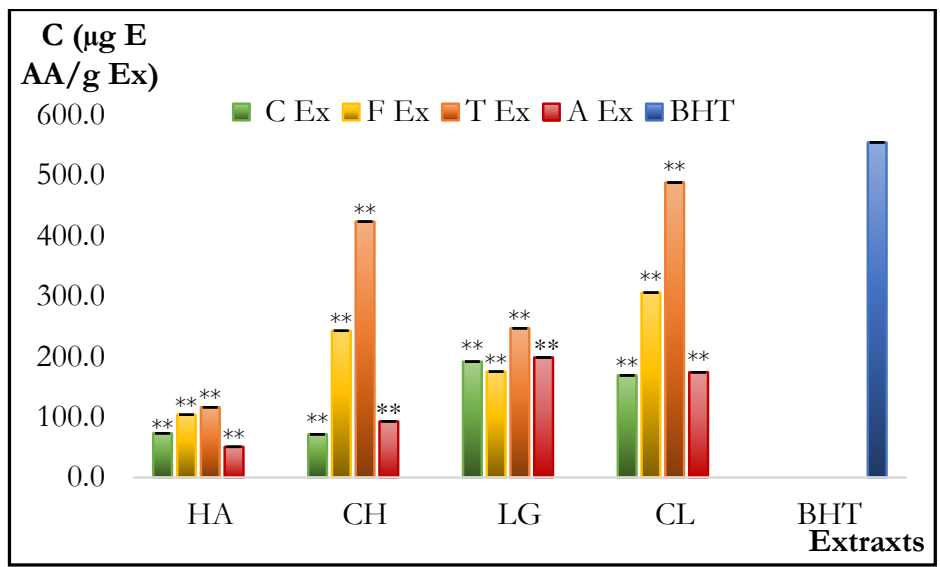

Figure 4. A comparison between different extracts and BHT in the total antioxidant capacity assay ${ }^{* *}$ : Significantly different at $\mathrm{p}<0.01$.

Generally, the antioxidant activity was of average values for antioxidant activities of the various extracts from the parasitic plants.

Determination of sun protection factor (SPF) by UV-Vis spectrophotometry

The SPF values of all extracts were made through the UV spectrophotometric method. The results are shown in Figure 5. Among the samples parasitic analyzed all of the extracts of the CL sample exhibit a median protection value ( $24.015 \pm 0.031$ to $27.434 \pm 0.020)$. While the extracts of the $\mathrm{CH}$ sample exhibit the low SPF value, when crude and anthocyanin extract, and medium when flavonoid and tannin extract $(11.050 \pm 0.011$ to $27.652 \pm 0.031)$. The average value of SPF, did show significant differences $(P \geq 0.01)$ between the extracts of parasitic plants among them; also, between her and her hosts.

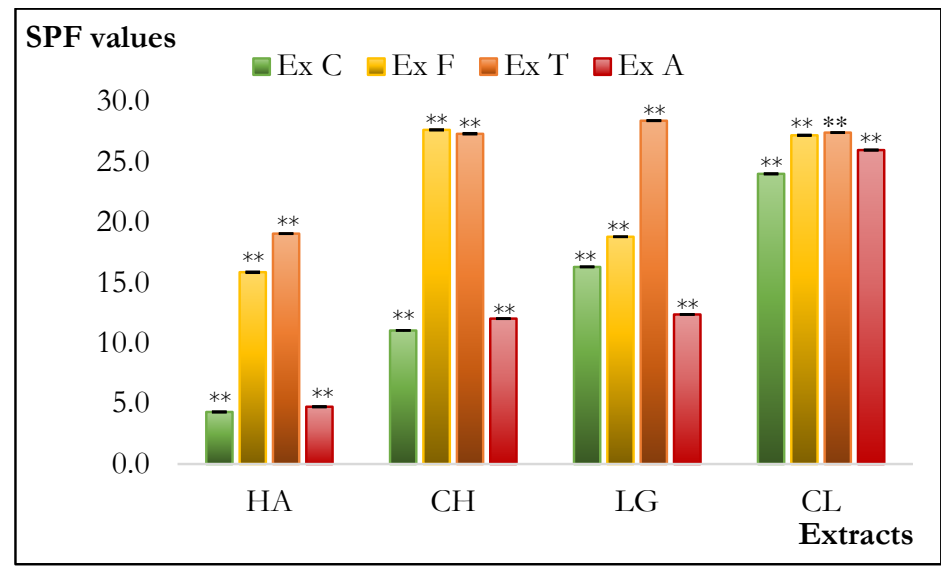

Figure 5. A comparison between different extracts in the SPF values **: Significantly different at $\mathrm{p}<0.01$. 


\section{Statistical analysis}

Through the results with $\mathrm{P}<0.01$, the host variation did not show any significant differences for both the physicochemical analysis and the quantitative and qualitative total content of polyphenols. While, the signification differences appeared through the antioxidant activity tests, especially between $\mathrm{CH}$ and its host, and between the two parasites $\mathrm{CH}$ and CL. As for SPF, significant differences were recorded for all extracts of studied plants.

\section{Discussion}

Hait et al. (2019) indicated that the amount of ash produced is related to the percentage of water in the plant matter; if the proportion is high, it reduces the amount of ash produced. In general, the mineral content in plants is an important index of possible environmental pollution and a potential indicator of the geographical origin of the plant (Silva et al., 2009).

In the plants, the $\mathrm{pH}$ values are due to the presence of organic substances such as starch; proteins; carbohydrates and organic acids, and inorganic ions, such as phosphate, sulfate and chloride (Silva et al., 2009). On the other hand, (Khelef et al., 2019) pointed out that the variation or similar $\mathrm{pH}$ value depends on the effect of those genetic factors of the plant.

The results show that the increase in ash content of the LG sample was accompanied by an increase in electrical conductivity. This is in agreement with previous studies of (Silva et al., 2009) that indicate a linear relationship is with a high correlation coefficient between these two criteria. As for its increase in CL plant, it can be attributed to the physiological relationship with LG plant. In general, the electrical conductivity of plants is closely related to the concentration of mineral salts and the quality of the electrolytes (Sarooshi et al., 1994).

Holoparasites, by definition, derive all of their carbon needs from the host (Joel, 2000), including the various carbohydrates species taking up and their accumulation. In a previous study, it was indicated that the concentrations of all sugars in parasite plants were between six- and eightfold higher than concentrations of the same compounds in the host, indicating a strong accumulation by the parasite (Joel et al., 2013). This is consistent with our results and may explain the marked variance of carbohydrate content between the parasite and its host.

In general, the different concentrations of carbohydrates depending on the metabolic and physiological state of the plant (Jan et al., 2019). Where Berger et al. (2007) indicates that parasitic plants destroy the normal organization of the host's metabolism.

An outstanding physiological characteristic of most parasites is their very high rates of transpiration, which often exceed that of the host by an order of magnitude. This maintains a gradient in leaf water potential towards the parasite and thus facilitates the flux of resources to the parasite. Therefore; high transpiration rates are a major component contributing to the lower water potentials of parasites and generating the hydrostatic gradient that facilitates the transfer of solutes from host to parasite. Including high concentrations of soluble carbohydrates have been implicated in the generation of an osmotic gradient between host and parasite (Stewart et al., 1990; Renuga Devi et al., 2015).

On the other hand, the exact proportion of molecules carbonic acquired depends on many factors including the growth stage of the parasite; wherein the stage of reproductive growth; the parasite plant needs high content sugars (Renuga Devi et al., 2015), host species and environmental availability of resources for host and parasite (Joel et al., 2013). Thus, it is reasonable to think that all these factors contributed to a greater or lesser extent to the existing variability in the carbohydrates content of the studied parasitic plants and their hosts. In addition to the negative physiological impact caused by the host-parasite relationship (Stewart et al., 1990). 
Comparing the obtained results with the previously published data of studies plants, we have found that the total polyphenols contents are not comparable with the other studies. As our results are much lower than those reported by them those studies. Therefore, the reason for these differences can be related to storage time, extrinsic (Bautista et al., 2015), genetic factors (Furuhashi et al., 2011), and physiological factors that have a strong influence on the quantity and quality of the compounds of polyphenols (Buchwald et al., 2015). Also, this difference in polyphenol content can be attributed to the choice of the solvent used in the extraction as well as to the origin of the plant studied, which makes comparison difficult (Chaouche et al., 2014).

Comparing $C$. violcea to its host $H$. articulatum, the higher polyphenol content may be related to their carbohydrate content. Where information on the transformation of sugar to polyphenol compounds can provide considerable knowledge on nutritional significance because the sugar moiety acts as a determinant of the bioavailability of these compounds (Piwowarczyk et al., 2020).

The $C$. violcea to its host $L$. guyonianum the host samples showed higher polyphenols content next to its parasites, this could be due the fact that a big part of the polyphenols is synthesized on stress periods against pathogens or symbiosis. This could indicate that the host plant has been able to resist the influence of the parasitic plant.

The HPLC quantification and identification back up the results from the spectrophotometric methods, due to a noticeable difference in the phenolic compound content on the parasitic samples. Where some studies indicated that there is no dependency from the host to the parasitic plant in the phenolic composition, besides other environmental factors such as weather, the season of the year and temperature that can affect the composition of the parasitic plant (Assanga et al., 2020).

Furthermore, it can be concluded that the polyphenols content of parasitic plants is not related to their quality and quantity in the host and that the host species can resist or tolerate the influence of biotic stress caused by the parasitic relationship.

The qualitative analysis by high-performance liquid chromatography showed the participation of the two parasites in each of gallic acid, chlorogenic acid, rutin and naringin, which may be attributed to the appearance of these compounds to their physiological role in this plant life.

Gallic acid acts as an important contributor to plant taste (Zhou et al., 2020). While Liu et al. (2013) isolated and identified gallic acid as an allelochemical.

The plant produces chlorogenic acid during responses against both biotic and abiotic stress (Xu et al., 2012), where Isman et al. (1982) reported that chlorogenic acid from tomato foliage inhibits the growth of $H$. zea larvae. It is also considered a factor coloring; it could be the reason for the appearance of the brown color when drying the plant. Where; the study of Isman et al. (1982) indicated browning to be correlated with polyphenol content, especially with chlorogenic acid, also a study (Vamos-Vigyazo et al., 1981) mentioned that chlorogenic acid was a factor to form colored red-brown, is due to the interaction between tyrosine and chlorogenic acid.

Rutin is a bioflavonoid; it is a vital nutritional component of plants (Enogieru et al., 2018). As rutin can be used as a coloring agent, and an oxidation inhibitor in plants (Kisa et al., 2016). while; study by Lucci et al. (2009) indicates that rutin and quercetin, are among the compounds protecting plants from cell damage during biotic and abiotic stresses, where confirmed the allelopathic effect of the two compounds. The study conducted by Barbosa et al. (1991) shows that rutin is less toxic, but has negative effects on the physiology and development of several insect herbivores.

Naringin is bioflavonoid present in plants. The physiological functions of naringin have rarely been investigated in plants.

The absence of vanillin, p-coumaric acid and quercetin in CL plant extract may be due to the different genetic origins of the host or it may be due to different environmental factors.

According to several studies, these compounds have demonstrated antioxidant activities that have different effects depending on the compound. Where Liang et al. (2016) indicated that chlorogenic acid is attributed to scavenging species of oxygen and nitrogen. While Chouikh et al. (2018) mentioned that $p$ - 
coumaric acid is good stimulation for antioxidant activity. Further, rutin was proven at Enogieru et al. (2018) that it has very high effectiveness against free radicals and oxidative stress. As well quercetin is one of the important bioflavonoids present in plants and is known to be good scavenging to ROS (Maalik et al., 2014). In addition, Naringin has been reporting to have antioxidant effects (Jung et al., 2003). This efficacy can explain what we recorded during the approved oxidative stress tests. Moreover, it has been shown to have a wide range of pharmacological and biological effects.

Several studies reported that polyphenols have a strong antioxidant activity, due to their properties which to act as reducing agents, hydrogen donors (Javanmardia et al., 2003), are capable of scavenging free radicals, and singlet oxygen quenchers (Chandra et al., 2014; Phuyal et al., 2020), metal chelators (Heshmati Afshar et al., 2012). In the present study, the results show that extracts flavonoids and tannins have the best scavenging power with both tests of DPPH and FRAP. Whereas, in the TAC test, that the anthocyanins extracts appear better total antioxidant capacity. This difference in the scavenging activity between the extracts could be because of the structure, quality, and functional capability of those compounds in the tested samples (Chouikh et al., 2018; Elazzouzi et al., 2019). Where; the previous researches showed that phenolic compounds with ortho- and para- dihydroxylation, a hydroxy and or a methoxy group or both have stronger antioxidant activity than simple polyphenols and also the presence of double bond conjugated and ketone groups in the whole molecule might play different polarities in the structure of the antioxidants and can be attributed to their antioxidant activity (Heshmati Afshar et al., 2012; Sroka, 2005).

\section{Conclusions}

The significant differences appeared through the antioxidant activity and SPF test host variation did not show any significant differences for both the physicochemical analysis and the quantitative and qualitative total content of polyphenols.

\section{Authors' Contributions}

$\mathrm{FA}, \mathrm{ABB}$ and $\mathrm{AC}$ designed and performed the experiments. FA and $\mathrm{AC}$ wrote the manuscript. $\mathrm{SN}$ and AT performed the HPLC analysis. ABD reviewed the manuscript. All authors read and approved the final manuscript.

\section{Acknowledgements}

This research received no specific grant from any funding agency in the public, commercial, or not-forprofit sectors.

\section{Conflict of Interests}

The authors declare that there are no conflicts of interest related to this article. 


\section{References}

Assanga SBI, Lujan LML, Ruiz JCG, Mccarty MF, Cota-Arce JM, Espinoza CLL, ... Ángulo DF (2020). Comparative analysis of phenolic content and antioxidant power between parasitic Phoradendron californicum (toji) and their hosts from Sonoran Desert. Results in Chemistry 2(100079):1-13. https://doi.org/10.1016/j.rechem.2020.100079

Barbosa P, Gross P, Kemper J (1991). Influence of plant allelochemicals on the tobacco hornworm and its parasitoid, Cotesia congregata. Ecology 72(5):1567-1575. https://doi.org/10.2307/1940956

Bautista I, Boscaiu M, Lidon A, Llinares JV, Lull C, Donat MP, Mayoral O, Vicente O (2015). Environmentally induced changes in antioxidant phenolic compounds levels in wild plants. Acta Physiologiae Plantarum 38(9):1-15. https://doi.org/10.1007/s11738-015-2025-2

Benesi IRM, Labuschagne MT, Dixon AG, Mahungu NM (2004). Stability of native starch quality parameters, starch extraction and root dry matter of cassava genotypes in different environments. Journal of the Science of Food and Agriculture 84(11):1381-1388. https://doi.org/10.1002/jsfa.1734

Berger S, Sinha AK, Roitsch T (2007). Plant physiology meets phytopathology: plant primary metabolism and plantpathogen interactions. Journal of Experimental Botany 58(16):4019-4026. https://doi.org/10.1093/jxb/erm298

Bougandoura A, Brigida D, Souad A, Monica S, Mekkioua R, Fiorentino A, (2016). Chemical constituents and in vitro anti-inflammatory activity of Cistanche violacea Desf. (Orobanchaceae) extract. Fitoterapia 109:248-253. https://doi.org/10.1016/j.fitote.2016.01.010

Buchwald W, Mordalski R, Kucharski WA, Gryszczynska A, Adamczak A (2015). Effect of fertilization on roseroot (Rhodiola rosea L.) yield and content of active compounds. Acta Scientiarum Polonorum Hortorum Cultus 14 (2):109-121.

Cam M, Hisil Y, Durmaz G (2009). Classification of eight pomegranate juices based on antioxidant capacity measured by four methods. Food Chemistry 112:721-726. https://doi.org/10.1016/j.foodchem.2008.06.009

Chandra S, Khan S, Avula B, Lata H, Yang MH, Elsohly MA, Khan1 IA (2014). Assessment of total phenolic and flavonoid content, antioxidant properties, and yield of aeroponically and conventionally grown leafy vegetables and fruit crops: a comparative study. Hindawi Publishing Corporation 2014:1-9. https://doi.org/10.1155/2014/253875

Chaouche TM, Haddouchi F, Ksouri R, Atik-Bekkara F (2014). Evaluation of antioxidant activity of hydromethanolic extracts of some medicinal species from South Algeria. Journal of the Chinese Medical Association 1-6. https://doi.org/10.1016/j.jcma.2014.01.009

Chaouche TM, Haddouchi F, Ksouri R, Medini F, Atik-Bekara F (2013). In vitro evaluation of antioxidant activity of the hydro-methanolic extracts of Juniperus oxycedrus subsp. oxycedrus. Phytothérapie 11(4):244-249. https://doi.org/10.1007/s10298-013-0779-5

Chouikh A, Alia F (2021). Phytochemical properties, antibacterial and anti-free radical activities of the phenolic extracts of Retama raetam (Forssk) Webb. \& Berthel. collected from Algeria Desert. Ovidius Universty Annals of Chemistry 32(1):33-39. https://doi.org/10.2478/auoc-2021-0005

Chouikh A, Alia F, Neffar S, Rebiai A, Adjal E, Chefrour A (2018). Evaluation of phenolic contents (quantitative and qualitative) and antioxidant activities in different physiological phases of Genista saharae Coss. \& Dur. growing in the Sahara of Algeria. Analele Universității din Oradea, Fascicula Biologie 25(2):115-121.

Chouikh A, Chemsa AE, Aounallah C, Aounallah I, Alia F (2020a). Phytochemical study, nutritive value, antioxidant and anti-inflammatory activities of phenolic extracts from desert plant Calligonum comosum L'Hér. Algerian Journal of Biosciences 1(2):68-75. https://doi.org/10.5281/zenodo.4395515

Chouikh A, Rebiai A (2020b). The influence of extraction method on the composition and analgesic activity of Calligonum comosum phenolic extracts. Ovidius University Annals of Chemistry 31(1):33-37. https://doi.org/10.2478/auoc-2020-0007

Dhanani T, Shah S, Gajbhiye NA, Kumar S (2013). Effect of extraction methods on yield, phytochemical constituents and antioxidant activity of Withania somnifera. Arabian Journal of Chemistry 1-7. https://doi.org/10.1016/j.arabjc.2013.02.015

Dubois M, Gilles KA, Hamilton JK, Rebers PT, Smith F (1956). Colorimetric method for determination of sugars and related substances. Analytical Chemistry 28:350-356. https://doi.org/10.1021/ac60111a017 
Dutra EA, Oliveira DA, Kedor-Hackmann ER, Santoro MI (2004). Determination of sun protection factor (SPF) of sunscreens by ultraviolet spectrophotometry. Brazilian Journal of Pharmaceutical Sciences 40(3):381-385.

El Atkia Y, Aouama I, El Kamaria F, Taroqa A, Lyoussia B, Talebb M, Abdellaouia A (2019). Total phenolic and flavonoid contents and antioxidant activities of extracts from Teucrium polium growing wild in Morocco. Materials Today: Proceedings 13:777-783.

Elazzouzi H, Zekri N, Zair T, Alaoui El Belghiti M (2019): Total phenolic and flavonoid contents of Anacyclus pyrethrum link plant extracts and their antioxidant activity. Karbala International Journal of Modern Science 5(4):279-287. https://doi.org/10.33640/2405-609X.1269

Enogieru AB, Haylett W, Hiss DH, Bardien S, Eko Ekpo O (2018). Rutin as a potent antioxidant: implications for neurodegenerative disorders. Hindawi. Oxidative Medicine and Cellular Longevity 2018:1-17. https://doi.org/10.1155/2018/6241017

Fahmy GM, El-Tantawy H, Abd El-Ghani MM (1996). Distribution, host range and biomass of two species of Cistanche and Orobanche cernua parasitizing the roots of some Egyptian xerophytes. Journal of Arid Environments 34:263-276.

Furuhashi T, Furuhashi K, Weckwerth W (2011). The parasitic mechanism of the holostemparasitic plant Cuscuta. Journal of Plant Interactions 6(4):207-219. https://doi.org/10.1080/17429145.2010.541945

Geetha M, Ponmozhi P, Saravanakumar M, Suganyadevi P (2011). Extraction of anthocyanin and analyzing its antioxidant properties from different onion (Allium cepa) varieties. International Journal of Research in Pharmaceutical Sciences 2(3):497-506.

Hait M, Bhardwaj AK, Kashyap NK, Vaishnav MM (2019). Physicochemical and phytochemical evaluation on non- areal part of Curcuma caesia. The Pharma Innovation Journal 8(5)514-517.

Heshmati Afshar F, Delazar A, Nazemiyeh H, Esnaashari S, Bamdad Moghadam S (2012). Comparison of the total phenol, flavonoid contents and antioxidant activity of methanolic extracts of Artemisia spicigera and $A$. splendens growing in Iran. Pharmaceutical sciences 18(3):165-170.

Huda-Faujan N, Noriham A, Norrakiah AS, Baji AS (2009). Antioxidant activity of plants methanolic extracts containing phenolic compounds. African Journal of Biotechnology 8(3):484-489.

Isman MB, Duffey SS (1982). Toxicity of tomato phenolic compounds to the fruit worm, Heliothis zea. Entomologia Experimentalis et applicata 31(4):370-376. https://doi.org/10.1111/j.1570-7458.1982.tb03162.x

Jan M, Shrivastava M (2019). Extraction of leaf pigments, carbohydrate and protein content from fresh leaves of Tinospora cordifolia (Willd.). SurajPunj Journal for Multidisciplinary Research 9(1):10-17.

Javanmardia J, Stushnoff C, Locke E, Vivanco JM (2003). Antioxidant activity and total phenolic content of Iranian Ocinum accessions. Food Chemistry 83:547-550. https://doi.org/10.1016/S0308-8146(03)00151-1

Joel DM (2000). The long-term approach to parasitic weeds control: manipulation of specific developmental mechanisms of the parasite. Crop Protection 19:753-758. https://doi.org/10.1016/S0261-2194(00)00100-9

Joel DM, Musselman LJ, Gressel J (2013). Parasitic Orobanchaceae: Parasitic Mechanisms and Control Strategies. Springer, Berlin, Germany, pp 513.

Jung UJ, Kim HJ, Lee JS, Lee MK, Kim HO, Park EJ, ... Choi MS (2003). Naringin supplementation lowers plasma lipids and enhances erythrocyte antioxidant enzyme activities in hypercholesterolemic subjects. Clinical Nutrition 22(6):561-568. https://doi.org/10.1016/S0261-5614(03)00059-1

Khelef Y, Chouikh A, Rebiai A, Neffar S, Chefrour A, Adjal E, Alia F (2019). Biochemical, quantitative and qualitative phenolic compounds, anti-free radical's activities of Calligonum comosum collected from different sites in the Algerian Desert. Biharean Biologist 13(191103):1-6.

Kisa D, Elmastas M, Ozturk L, Kayir O (2016). Responses of the phenolic compounds of Zea mays under heavy metal stress. Applied Biological Chemistry 59(6):813-820. https://doi.org/10.1007/s13765-016-0229-9

Le Floch L, Boulos E, Vela E, Ghrabi-Gammar Z, Daoud-Bouattour A, Ben Saad-Limam S (2010). Catalogue synonymique commenté de la flore de Tunisie. Republique Tunisienne, pp 272.

Liang N, Kitts DD (2016). Role of chlorogenic acids in controlling oxidative and inflammatory stress conditions. Nutrients 8(16):1-20. https://doi.org/10.3390/nu8010016

Liu Y, Li F, Huang Q (2013). Allelopathic effects of gallic acid from Aegiceras corniculatum on Cyclotella caspia. Journal of Environmental Sciences 25 (4):776-784. https://doi.org/10.1016/S1001-0742(12)60112-0

Longo L, Scardino A, Vasapollo G, (2007). Identification and quantification of anthocyanins in the berries of Pistacia lentiscus L., Phillyrea latifolia L. and Rubia peregrina L. Innovative Food Science and Emerging Technologies 8:360-364. https://doi.org/10.1016/j.ifset.2007.03.010 
Lucci N, Mazzafera P (2009). Distribution of rutin in fava d'anta (Dimorphandra mollis) seedlings under stress. Journal of Plant Interactions 4(3):203-208. https://doi.org/10.1080/17429140802707035

Maalik A, Khan FA, Mumtaz A, Mehmood A, Azhar S, Atif M, ... Tariq I (2014). Pharmacological applications of quercetin and its derivatives: a short review. Tropical Journal of Pharmaceutical Research September 13(9):1561-1566.

Mbanga L, Mpiana PT, Mbala M, Ilinga L, Ngoy B, Mvingu K, Mulenga M (2015). Comparative in vitro Sun Protection Factor (SPF) values of some herbal extracts found in Kinshasa by ultraviolet spectrophotometry. Journal of Physical and Chemical Sciences 2(4):1-6.

Ningqun W, Shaozhen J, Hao Z, Shanshan M, Lumin Q, Xianglan J, (2017). Herba cistanches: Anti-aging. Aging and Disease, China 8(6):753. https://doi.org/10.14336/AD.2017.0720

Penning SC, Callaway RM (2002). Parasitic plants: parallels and contrasts with herbivores. Review in Oecologia 131:479489. https://doi.org/10.1007/s00442-002-0923-7

Phuyal N, Jha PK, Raturi PP, Rajbhandary S (2020). Total phenolic, flavonoid contents, and antioxidant activities of fruit, seed, and bark extracts of Zanthoxylum armatum DC. The Scientific World Journal 2020:1-7. https://doi.org/10.1155/2020/8780704

Piwowarczyk R, Ochmian I, Lachowicz S, Kapusta I, Sotek Z, Błaszak M (2020). Phytochemical parasite-host relations and interactions: a Cistanche armena case study. Science of the Total Environment 716(137071):1-11. https://doi.org/10.1016/j.scitotenv.2020.137071

Rebiai A, Lanze T, Chouikh A (2015). Physicochemical and biochemical properties of honey bee products in south Algeria. Science Study \& Research 16 (2):133-142.

Renuga Devi M, Krishna Kumari S (2015). Quantitative estimation of primary and secondary metabolites in hot aqueous extract of Pleurotus sajor caju. Journal of Pharmacognosy and Phytochemistry 4 (3):198-202.

Sarooshi RA, Cresswel GC (1994). Effects of hydroponic solution composition, electrical conductivity and plant spacing on yield and quality of strawberries. Australian Journal of Experimental Agriculture 34:529-535. https://doi.org/10.1071/EA9940529

Schalka S, Reis VMS (2011). Sun protection factor: meaning and controversies. Anais Brasileiros de Dermatologia 86(3):507-515. https://doi.org/10.1590/S0365-05962011000300013

Silva LR, Videira R, Monteiro AP, Valentão P, Andrade PB (2009). Honey from Luso region (Portugal): Physicochemical characteristics and mineral contents. Microchemical Journal 93:73-77. https://doi.org/10.1016/j.microc.2009.05.005

Sroka Z (2005). Antioxidative and antiradical properties of plant phenolics. Zeitschrift für Naturforschung C 60(1112):833-843. https://doi.org/10.1515/znc-2005-11-1204

Stewart GR, Press MC (1990). Biochemistry of parasitic angiosperms. Annual Review of Plant Physiology and Plant Molecular Biology 41:127-151. https://doi.org/10.1146/annurev.pp.41.060190.001015

Suresh GK, Harinath NM (2010). Estimation of tannins in different parts of Memecylon umbellatum Burm. Journal of Pharmacy Research 3(3):554-556.

Truong D, Nguyen D, Anh Ta NT, Bui AV, Do TH, Nguyen HC (2019). Evaluation of the use of different solvents for phytochemical constituents, antioxidants, and in vitro anti-inflammatory activities of Severinia buxifolia Hindwai. Journal of Food Quality 8178294:1-9. https://doi.org/10.1155/2019/8178294

Vamos-Vigyazo L, Haard NF (1981). Polyphenol oxidases and peroxidases in fruits and vegetables. C. R. C. Critical Reviews in Food Science and Nutrition 15(1):49-127. https://doi.org/10.1080/10408398109527312

Xu JG, Hu QP, Liu Y (2012). Antioxidant and DNA-protective activities of chlorogenic acid isomers. Journal of Agricultural and Food Chemistry 60:11625-11630. https://doi.org/10.1021/jf303771s

Zengin G, Aktumsek A, Guler GO, Cakmak YS, Yildiztugay E (2011). Antioxidant properties of methanolic extract and fatty acid composition of Centaurea urvillei DC. subsp. hayekiana Wagenitz. Records of Natural Products 5(2):123-132.

Zhang X, Jeza VT, Pan Q (2008). Sabmonelle Typhi: Form antihuman pathogen to a vector. Cellular et Molecular Immunology 5(2):91-97. https://doi.org/10.1038/cmi.2008.11

Zhou Z, Zeng L, Chen Y, Wang X, Liao Y, Xiao Y, Fu X, Yang Z (2020). Metabolism of gallic acid and its distributions in tea (Camellia sinensis) plants at the tissue and subcellular levels. International Journal of Molecular Sciences 21(5684):1-13. https://doi.org/10.3390/ijms21165684 
OPEN ACCESS

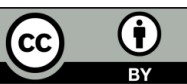

The journal offers free, immediate, and unrestricted access to peer-reviewed research and scholarly work. Users are allowed to read, download, copy, distribute, print, search, or link to the full texts of the articles, or use them for any other lawful purpose, without asking prior permission from the publisher or the author.

License - Articles published in Notulae Scientia Biologicae are Open-Access, distributed under the terms and conditions of the Creative Commons Attribution (CC BY 4.0) License.

(c) Articles by the authors; SHST, Cluj-Napoca, Romania. The journal allows the author(s) to hold the copyright/to retain publishing rights without restriction. 